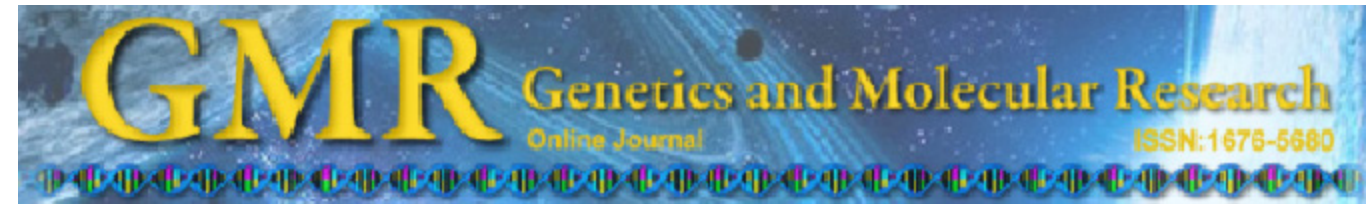

\title{
Link to retraction noticed \\ Absolute quantification of free tumor cells in the peripheral blood of gastric cancer patients
}

\author{
N. Bayat ${ }^{1}$, M.M. Mokhtari ${ }^{1}$, M. Rezaei-Tavirani', \\ A. Baradaran-rafii ${ }^{2}$, S. Rahman Zadeh ${ }^{1}$, S. Heidari-Keshel ${ }^{1}$ \\ and F. Ghasemvand ${ }^{1}$ \\ ${ }^{1}$ Proteomics Research Center, Faculty of Paramedical Sciences, \\ Shahid Beheshti University of Medical Sciences, Tehran, Iran \\ ${ }^{2}$ Ophtalmic Research Center, Shahid Beheshti University of Medical Sciences, \\ Tehran, Iran \\ Corresponding author: S. Heidari-Keshel \\ E-mail: saeed_heidari@spu. \\ Genet. Mol. Res. 13 (2): 4425-4432 (2014) \\ Received September 5, 2013 \\ Accepted May 5, 2014 \\ Published June 16, 2014 \\ DOI http://dx.doi.org/10.4238/2014.June.16.1 \\ ABSTRACT. Gastric cancer remains the third most common cancer in \\ the world. Metastatic disease is a major cause of death in about half of the \\ patients; therefore, early diagnosis is crucial for successful outcome. This \\ study applied a sensitive method for the detection of circulating tumor cells \\ using specific tumor markers for early detection. A total of 80 blood samples \\ from 40 patients and 40 age-matched healthy controls were collected for the \\ study. Circulating mRNA levels of two tumor markers, tumor endothelial \\ marker 8 (TEM-8) and carcinoembryogenic antigen (CEA) were evaluated \\ using absolute quantitative real-time PCR assay in the Stratagene Mx-3000P \\ real-time PCR system. GAPDH was used to normalize the data. TEM-8 \\ and CEA were detected in patients' blood more than in controls, 22/40 vs \\ $9 / 40, \mathrm{P}=0.005$, and $30 / 40 v s 11 / 40, \mathrm{P}=0.008$, respectively. The mRNA \\ level of these markers in patients was significantly higher in comparison to \\ normal controls $(\mathrm{P}=0.018,0.01)$. This panel showed an overall sensitivity \\ of $64 \%$ and specificity of $73 \%$. Statistical analysis for demographic variants \\ did not show any significant differences. Both markers were detected more \\ frequently and in significantly higher levels in blood samples of patients
}


compared to samples from normal individuals. Copy number of CEA and TEM-8 mRNA, as detected by real-time quantitative PCR, appears to be a promising marker to evaluate the risk of tumor spread.

Key words: Gastric Cancer; Tumor markers; TEM-8; Real-time PCR; CEA

\section{INTRODUCTION}

Nearly 600,000 individuals die every year from the third most prevalent tumor type in the world, gastric cancer (Burt et al., 1995; Pisani et al., 1999). Gastric cancer is also one of the most frequent malignancies in Iran. As several researchers have reported, in about 40$50 \%$ of gastric cancer patients who undergo tumor resection, there is a subsequent metastasis through the bloodstream or lymphatic circulation to other organs, which decreases the 5-year survival of these patients (Yeh et al., 2006). Therefore, early detection with accurate methods is significantly needed (Xu et al., 2006).

The best therapeutic method is elimination of the tumor in early stages. The feasibility of satisfactory treatment after tumor resection depends on tumor stage. The TMN staging system is the conventional method for tumor stage investigation, although this system can determine tumor prognosis, it has some treatment failures (Silva et al., 2002). Consequently several sensitive methods for molecular staging using high-throughput techniques have been developed to distinguish micrometastasis (Silva et al., 2002). Molecular staging could be evaluated in lymph nodes, bone marrow and blood of the patients (Bustin, 2000). In recent past, real-time PCR monitoring systems have been introduced to identify the mRNA of circulating tumor cells in cancer patients (Holland et al., 1991). This approach allows precise quantification of initial template copy number based on the fact that the cycle number at which the sample fluorescence exceeds the background level is conversely correlated with the starting copy number (Gerard et al., 1998). Markers used for PCR detection of tumor cells are dependent upon particular traits of the tissue, from which the tumor originates. For instance carcinoembryonic antigen (CEA) described as a protein with an oncofetal expression pattern, may act as hemophilic and heterothallic cell adhesion molecule when expressed on the tumor cell surface. It also has significant functions throughout embryogenesis as well as in tumor development (Sehrewe et al., 1990). Another marker, tumor epithelial marker 8 (TEM-8) is evidently unique among other cell surface TEMs as its expression has not been discerned throughout other forms of physiologic angiogenesis in adults (Nanda and St Croix, 2004). TEM-8 is a type I transmembrane protein consisting of 564 amino acids, and may have a role in the interaction of cells with the surrounding extracellular matrix (Rmali et al., 2005).

In the present study, we applied quantitative real-time RT-PCR to detect CEA and TEM-8 mRNA expression in peripheral blood of gastric cancer patients to investigate the sensitivity of these markers in detecting microinvasion.

\section{MATERIAL AND METHODS}

\section{Study subjects}

Between March 2010 and February 2012, 80 blood samples from 40 patients, before 
undergoing surgery or other therapeutic procedures including preoperative chemotherapy or radiotherapy, and 40 healthy volunteers were collected. All patients and healthy volunteers were informed about the study and gave written consent for the investigation in accordance with ethical guidelines.

\section{RNA extraction and cDNA synthesis}

Five milliliters of blood samples were diluted with $5 \mathrm{~mL}$ phosphate-buffered saline, and peripheral blood mononuclear cells collected using lymphocyte separation medium. Total cell RNA was extracted from the cells by conventional methods using Trizol reagent (Roche, Applied Sciences, Indianapolis, IN, USA) according to manufacturer instructions. RNA quality was evaluated by an ultraviolet absorption characteristics, and concentration was determined spectrophotometrically on the basis of optical density (OD) at $260 \mathrm{~nm}$. First-strand cDNA was synthesized from $1 \mu \mathrm{g}$ total RNA and oligo (dT) ${ }_{18}$ as amplification primers using the RT-PCR kit (Fermentas, Vilnius, Lithuania).

\section{Construction of standards}

MAD-MB321 and HT29 cell lines were grown in RPMI-1640 medium supplemented with $10 \%$ fetal bovine serum at $37^{\circ} \mathrm{C}$ in a $5 \% \mathrm{CO}_{2}$ air environment. When grown to a confluent monolayer, the MAD-MB321 and HT29 cells were harvested and used for the TEM-8 and CEA standard curves, respectively. To prepare the standard curve, cDNAs were amplified and inserted into the pTZR/57 vector (Fermentas, Vilnius, Lithuania). After cloning, recombinant vectors were extracted, linearized with SacI and serially diluted. Copy numbers were calculated for all standards by the following formula (Schmittgen and Livak, 2008):

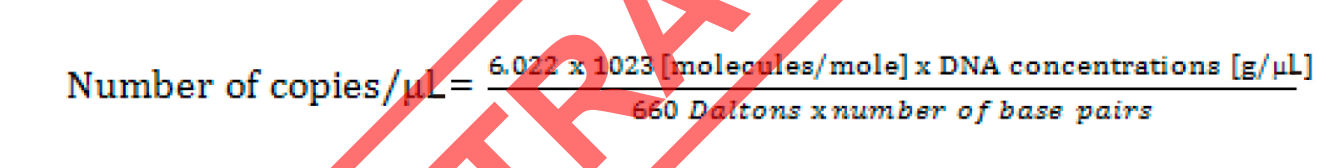

where $6.022 \times 10^{23}$ [molecules $/$ mole] $=$ Avogadro's number and $660 \mathrm{Da}=$ average weight of a single base pair

\section{Quantitative real-time RT-PCR}

Cloning and real-time primers for CEA, TEM- 8 and GAPDH as an internal control, and a fluorogenic probe for TEM-8 were designed by the AlleleID software as described in Table 1.

To prepare the standard curves, CEA and TEM- 8 cDNAs were amplified and inserted into the pTZR/57 vector (Fermentas). After cloning, recombinant vectors were extracted, linearized with $\mathrm{SacI}$ and serially diluted. Copy number of plasmid was calculated on the basis of $\mathrm{OD}$ at $280 \mathrm{~nm}$, length of recombinant vector and Avogadro's number.

Real-time PCR was performed in the Stratagene Mx-3000P (Stratagene, La Jolla, CA, USA) machine. SYBR green was used for amplification of CEA and TaqMan probes utilized for TEM-8 in a total volume of $20 \mu \mathrm{L}$ using absolute quantitative (by $\Delta \mathrm{ct}$ ) module. For CEA, each reaction consisted of the following: $10 \mu \mathrm{L}$ SYBR green, $2 \mu \mathrm{L}$ cDNA, $0.5 \mu \mathrm{L} 10 \mu \mathrm{L}$ of each primer, and $7 \mu \mathrm{L}$ RNAse-free water. Thermal cycling conditions were $10 \mathrm{~min}$ at $95^{\circ} \mathrm{C}$ 
N. Bayat et al.

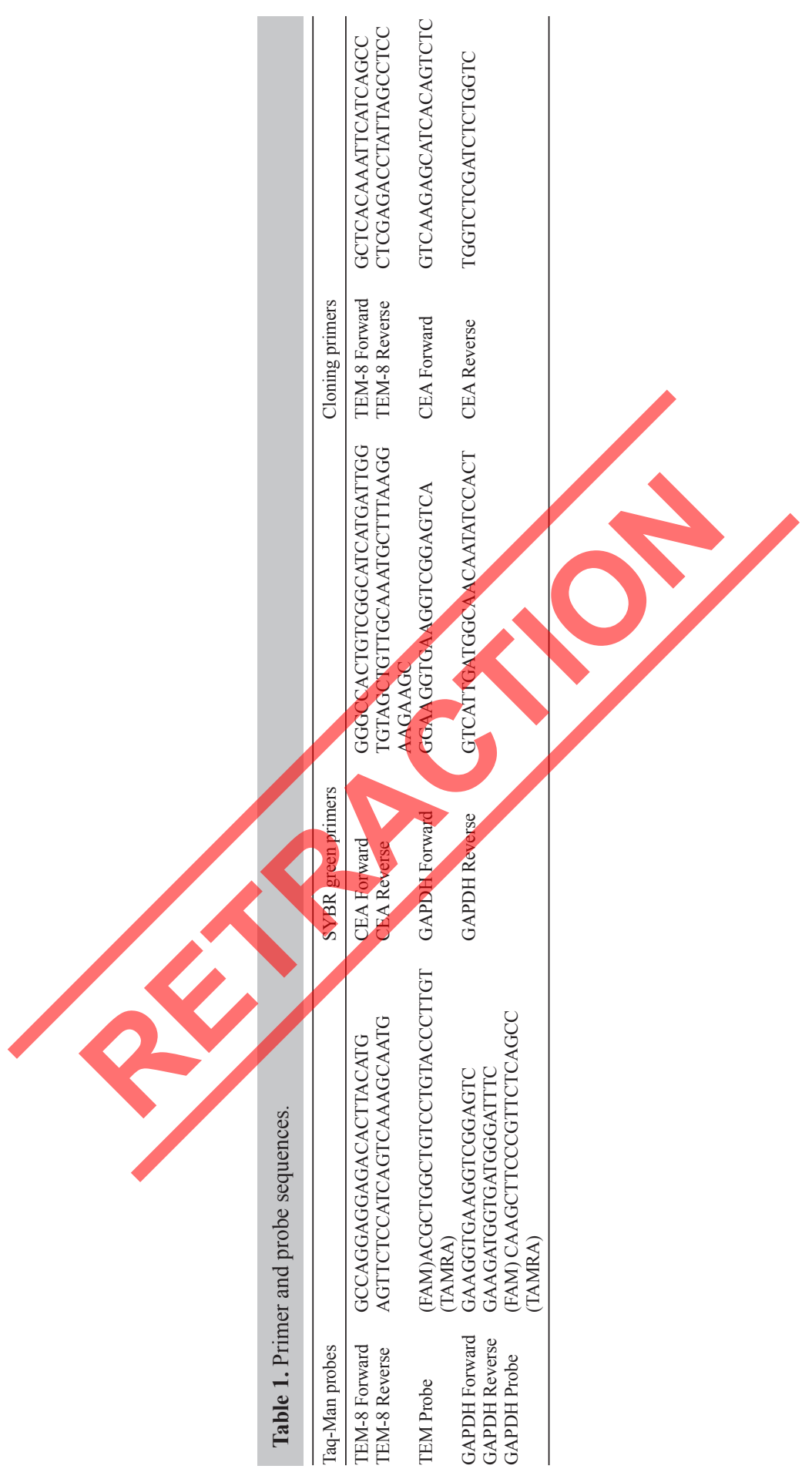

Genetics and Molecular Research 13 (2): 4425-4432 (2014) 
followed by 45 cycles at $95^{\circ} \mathrm{C}$ for $40 \mathrm{~s}, 62^{\circ} \mathrm{C}$ for $40 \mathrm{~s}$, and $72^{\circ} \mathrm{C}$ for $40 \mathrm{~s}$. For TEM- 8 , the PCR contained $10 \mu \mathrm{L}$ TaqMan master mix, $2 \mu \mathrm{L}$ cDNA, $0.2 \mu \mathrm{L}$ probe, $0.6 \mu \mathrm{L} 10 \mu \mathrm{M}$ of each primer, and 7.2 $\mu \mathrm{L}$ RNAse-free water. The thermal cycle program was as follows: $10 \mathrm{~min}$ at $95^{\circ} \mathrm{C}$ followed by 45 cycles at $95^{\circ} \mathrm{C}$ for $30 \mathrm{~s}, 62^{\circ} \mathrm{C}$ for $40 \mathrm{~s}$ and $72^{\circ} \mathrm{C}$ for $30 \mathrm{~s}$. GAPDH was used as the endogenous control to normalize the data.

\section{Statistical analysis}

All data were analyzed using SPSS version 14 (SPSS Inc, Chicago, IL, USA) and P < 0.05 was considered to be statistically significant. The $t$-test was used to investigate the association of copy number with demographic features of gender, tumor location, stage and grade, and also lymph node involvement. Pearson's correlation was used for age and age of onset and tumor size.

\section{RESULTS}

A total of 40 patients with primary gastric cancer (male:female $=30: 10$; mean age $=57.4$ \pm 18.76 years) and 40 healthy controls (male:female $=24: 16$; mean age $=57.3 \pm 7.4$ years) were recruited in the study. Most patients $(75 \%)$ had intact lymph nodes representing localized tumors (Table 2).

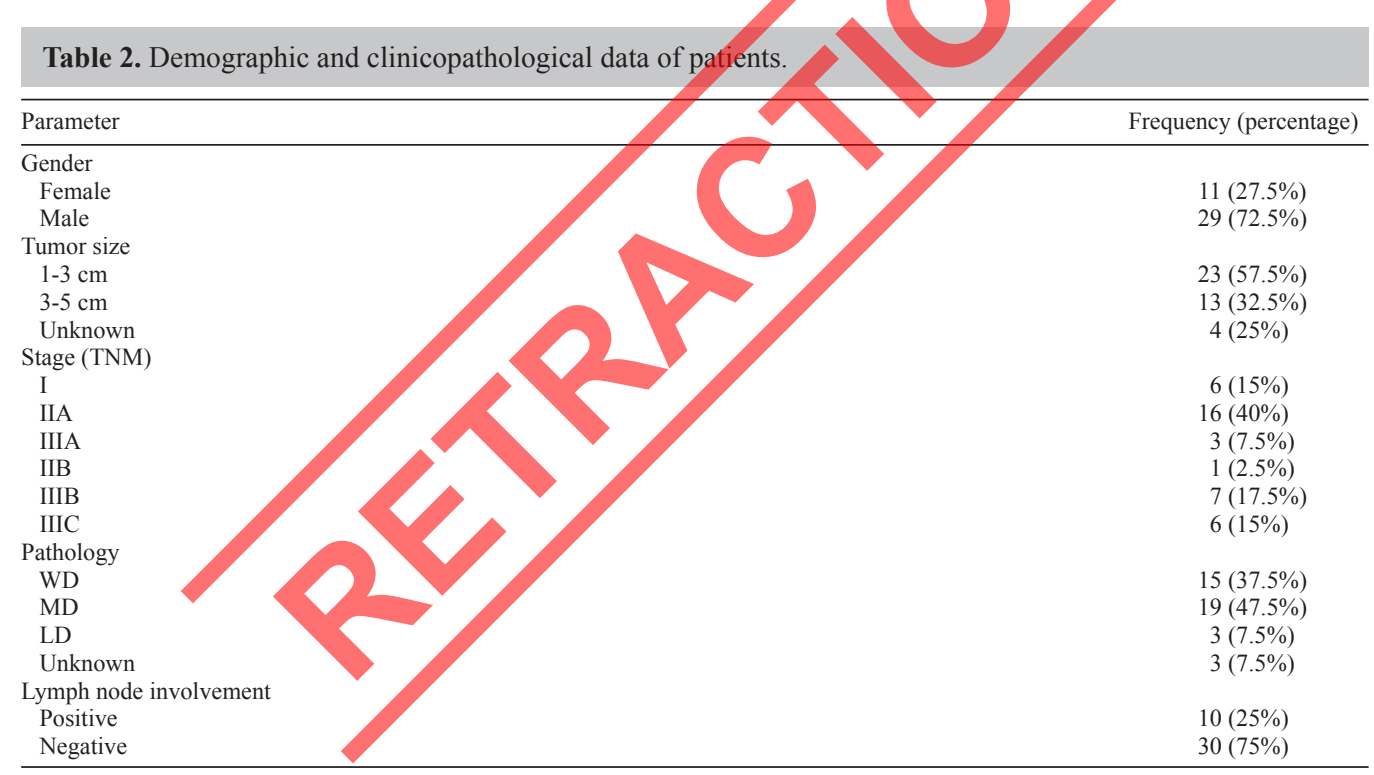

Real-time PCR analysis of circulating mRNA levels of the tumor markers TEM-8 and CEA revealed the presence of these markers in peripheral blood significantly more in the patients than in the controls, $22 / 40$ vs $9 / 40(\mathrm{P}=0.005)$ for TEM-8 and 30/40 vs 11/40 $(\mathrm{P}=0.008)$ for CEA, respectively. The mRNA level of these markers in patients was significantly higher in comparison to normal controls $(\mathrm{P}=0.018, \mathrm{P}=0.01$, respectively) (Figure 1$)$. These two markers showed overall sensitivity of $64 \%$ and specificity of $73 \%$ in circulating tumor cells. Furthermore, the TEM- 8 copy number was also higher in cases with lymph node metastasis $(\mathrm{Z}=1.831, \mathrm{P}=0.069)$. 


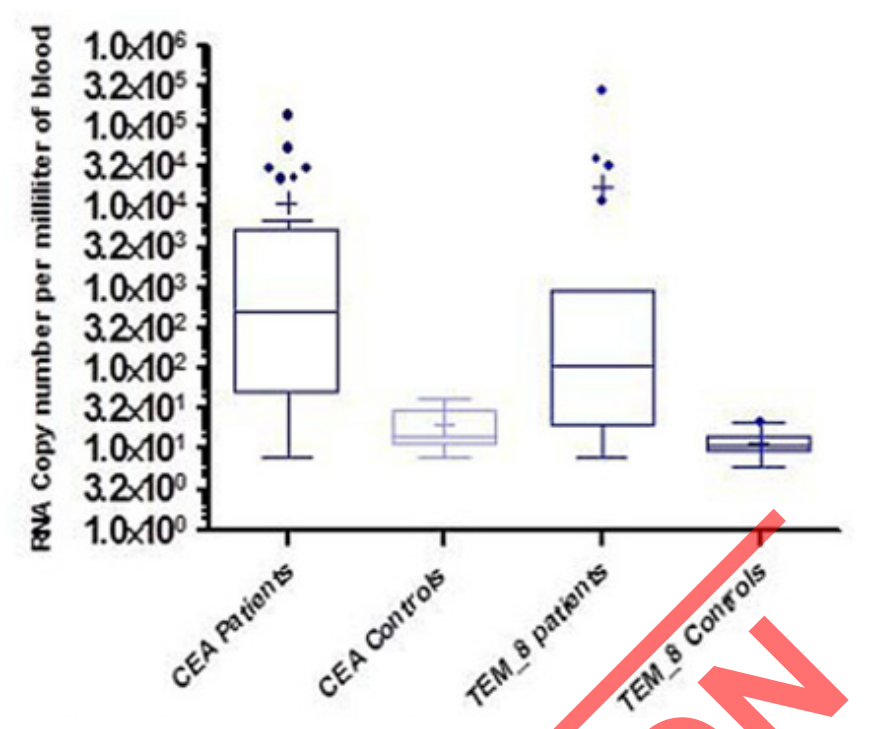

Figure 1. Quantification of TEM-8 and CEA RNA in patients and controls. Copy number of each marker is shown in $\mathrm{mL}$ of peripheral blood. Dots refer to the post-hoc Turkey analysis.

\section{DISCUSSION}

Before metastasis become evident, some tumor cells break away from the tumor and spread through lymph nodes and blood to distant organs (Silva et al., 2002). Although most circulating tumor cells are not viable, a few remaining cells have the capability to form metastasis (Shen et al., 2008). Monitoring these cells in the blood and lymph nodes should be an appropriate approach for metastasis prediction and can be utilized as a new staging method. To date, only a few sensitive techniques have been available for detection of disseminated tumor cell in the blood sample of gastric patients, involving flow cytometry (Shen et al., 2008), immunohistochemistry (Turner et al, 2001), and RT-PCR (Ghossein et al., 1999). In contrast, qRT-PCR integrates the high-efficiency of PCR and high sensitivity and accurate quantification of spectral analysis. The efficacy of qRT-PCR assay for the detection of circulating tumor cells in blood depends on the balance of sensitivity and specificity. In other words, the assay must be sensitive to detect yery small numbers of tumor cells and must be specific enough to detect transcripts for those derived from tumor cells (Zieglschmid et al., 2005). There are tumor markers detectable in gastric patients that can predict early stages of metastasis; some of these markers are detectable in lymph nodes, while others are present in peripheral blood (Zieglschmid et al., 2005; Ohlsson et al., 2006). The detection rate of circulating tumor cells in peripheral blood from gastric cancer patients is in the range from 27 to $88 \%$ (Conzelmann et al., 2005; Wang et al., 2006; Lloyd et al., 2006). Although many markers have been investigated individually or in several panels, the lack of both sensitivity and specificity was shown in these experiments. Therefore many investigators have studied different genetic alternations. To date, the lack of a single specific tumor marker for reliable detection of gastric cancer patients remains a fundamental problem. The experimental results showed that tumor cells were more frequently present in the circulation of gastric cancer patients, which can predict devel- 
oping metastasis in the near future. Therefore, this method may be utilized to detect the spread of the tumor and distant metastasis before any other imaging or pathology approach. Perhaps, future investigations on tumor signaling pathways and cancer stem cells will help us in developing a single marker or a panel of markers for early detection of gastric cancer. Another issue under debate is the clinical application of this method. Future cohort studies monitoring larger numbers of patients seem to be necessary to evaluate the prognostic value of each marker and to determine the subgroup of patients with high levels of specific tumor marker, who require more aggressive treatment, including more potent chemotherapeutic regimens.

\section{ACKNOWLEDGMENTS}

Research supported by the Beheshti University (\#UN125). The authors kindly thank all the colleagues who contributed to this study. This project is part of the master's thesis of Neda Bayat.

\section{REFERENCES}

Burt RW, DiSario JA and Cannon-Albright L (1995). Genetics of colon cancer: impact of inheritance on colon cancer risk. Annu. Rev. Med. 46: 371-379.

Bustin SA (2000). Absolute quantification of mRNA using real-time reverse transcription polymerase chain reaction assays. J. Mol. Endocrinol. 25: 169-193.

Conzelmann M, Linnemann U and Berger MR (2005). Molecular detection of clinical colorectal cancer metastasis: how should multiple markers be put to use? Int. J. Colorectal. Dis. 20: 137-146.

Gerard CJ, Olsson K, Ramanathan R, Reading C, et al. (1998). Improved quantitation of minimal residual disease in multiple myeloma using real-time polymerase chain reaction and plasmid-DNA complementarity determining region III standards. Cancer Res. 58: 3957-3964.

Ghossein RA, Bhattacharya S and Rosai J (1999). Molecular detection of micrometastases and circulating tumor cells in solid tumors. Clin. Cancer Res. 5: 1950-1960.

Holland PM, Abramson RD, Watson R and Gelfand DH (1991). Detection of specific polymerase chain reaction product by utilizing the $5^{\prime} \rightarrow 3^{\prime}$ exonuclease activity of Thermus aquaticus DNA polymerase. Proc. Natl. Acad. Sci. U. S. A. 88: 7276-7280.

Lloyd JM, McIver CM, Stephenson SA, Hewett PJ, et al. (2006). Identification of early-stage colorectal cancer patients at risk of relapse post-resection by immunobead reverse transcription-PCR analysis of peritoneal lavage fluid for malignant cells. Clin. Cancer Res. 12: 417-423.

Nanda A and St Croix B (2004). Tumorendothelial markers: new targets for cancer therapy. Curr. Opin. Oncol. 16: 44-49.

Ohlsson L, Hammarstrom ML, Israelsson A, Naslund L, et al. (2006). Biomarker selection for detection of occult tumour cells in lymph nodes of colorectal cancer patients using real-time quantitative RT-PCR. Br. J. Cancer 95: 218-225.

Pisani P, Parkin DM, Bray F and Ferlay J (1999). Estimates of the worldwide mortality from 25 cancers in 1990. Int. J. Cancer 83: 18-29.

Rmali KA, Puntis MC and Jiang WG (2005). TEM-8 and tubule formation in endothelial cells, its potential role of its vW/ TM domains. Biochem. Biophys. Res. Commun. 334: 231-238.

Schmittgen TD and Livak KJ (2008). Analyzing real-time PCR data by the comparative $\mathrm{C}_{\mathrm{T}}$ method. Nat. Protoc. 3: 1101-1108.

Schrewe H, Thompson J, Bona M, Hefta LJ, et al. (1990). Cloning of the complete gene for carcinoembryonic antigen: analysis of its promoter indicates a region conveying cell type-specific expression. Mol. Cell Biol. 10: 2738-2748.

Shen C, Hu L, Xia L and Li Y (2008). Quantitative real-time RT-PCR detection for survivin, CK20 and CEA in peripheral blood of colorectal cancer patients. Jpn J. Clin. Oncol. 38: 770-776.

Silva JM, Rodriguez R, Garcia JM, Munoz C, et al. (2002). Detection of epithelial tumour RNA in the plasma of colon cancer patients is associated with advanced stages and circulating tumour cells. Gut 50: 530-534.

Turner RR, Giuliano AE, Hoon DS, Glass EC, et al. (2001). Pathologic examination of sentinel lymph node for breast carcinoma. World J. Surg. 25: 798-805.

Wang JY, Wu CH, Lu CY, Hsieh JS, et al. (2006). Molecular detection of circulating tumor cells in the peripheral blood of patients with colorectal cancer using RT-PCR: significance of the prediction of postoperative metastasis. World J. Surg. 30: 1007-1013. 
Xu D, Li XF, Zheng S and Jiang WZ (2006). Quantitative real-time RT-PCR detection for CEA, CK20 and CK19 mRNA in peripheral blood of colorectal cancer patients. J. Zhejiang Univ. Sci. B 7: 445-451.

Yeh CS, Wang JY, Wu CH, Chong IW, et al. (2006). Molecular detection of circulating cancer cells in the peripheral blood of patients with colorectal cancer by using membrane array with a multiple mRNA marker panel. Int. J. Oncol. 28: 411-420.

Zieglschmid V, Hollmann C and Bocher O (2005). Detection of disseminated tumor cells in peripheral blood. Crit. Rev. Clin. Lab. Sci. 42: 155-196.

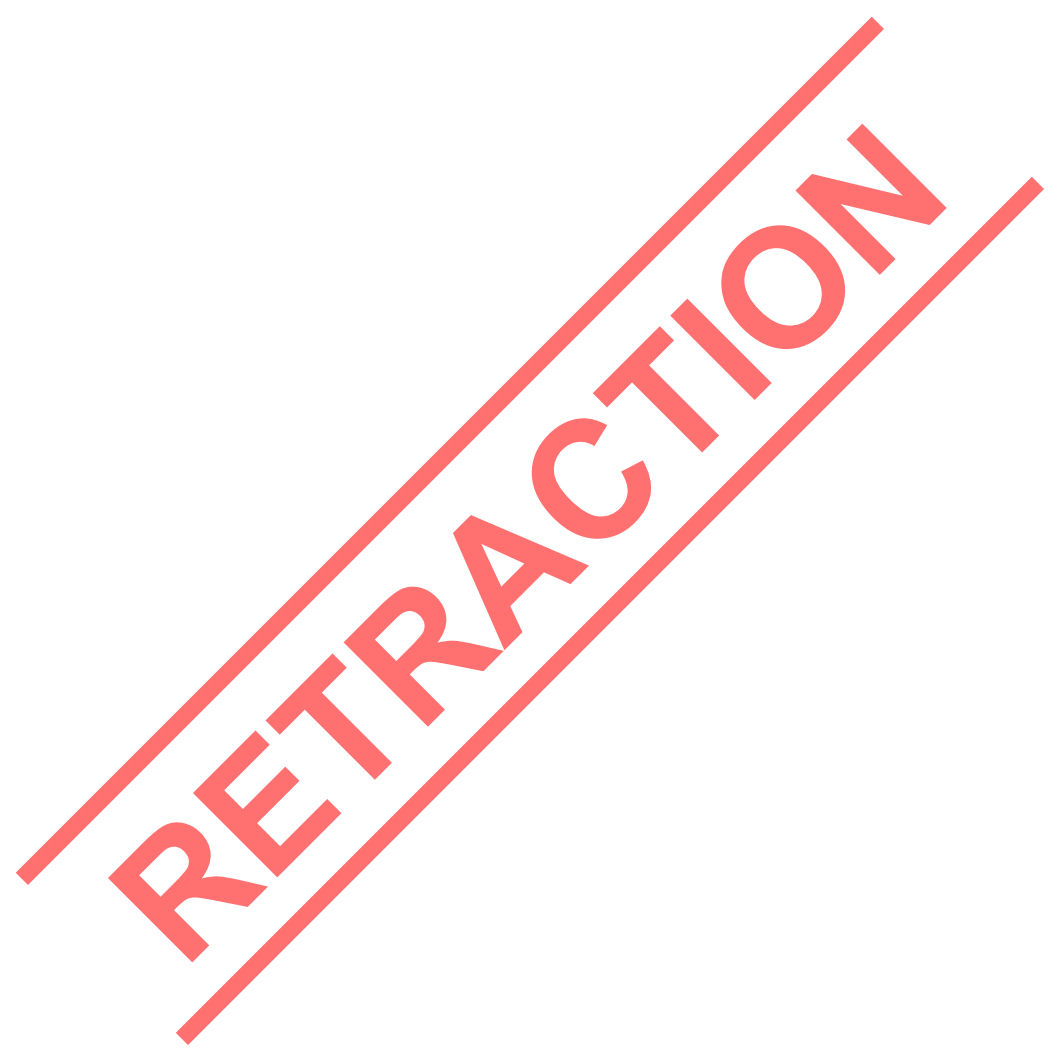

Genetics and Molecular Research 13 (2): 4425-4432 (2014) 